\title{
Cross-sensitization to Artemisia and Ambrosia pollen allergens in an area located outside of the current distribution range of Ambrosia
}

\author{
Łukasz Grewling ${ }^{1}$, Dorota Jenerowicz², Paweł Bogawski³ ${ }^{3}$ Matt Smith ${ }^{4}$, Małgorzata Nowak ${ }^{1,2}$, Agata Frątczak ${ }^{5}$, \\ Magdalena Czarnecka-Operacz ${ }^{2}$
}

\begin{abstract}
'Laboratory of Aeropalynology, Faculty of Biology, Adam Mickiewicz University, Poznan, Poland ${ }^{2}$ Department of Dermatology, Poznan University of Medical Science, Poznan, Poland ${ }^{3}$ Laboratory of Biological Spatial Information, Faculty of Biology, Adam Mickiewicz University, Poznan, Poland ${ }^{4}$ Institute of Science and the Environment, University of Worcester, Worcester, United Kingdom ${ }^{5}$ Department of Plant Taxonomy, Faculty of Biology, Adam Mickiewicz University, Poznan, Poland
\end{abstract}

Adv Dermatol Allergol 2018; XXXV (1): 83-89 DOI: https://doi.org/10.5114/ada.2018.73167

\begin{abstract}
Introduction: The role of long-distance transported (LDT) Ambrosia pollen in inducing new sensitization and affecting sensitization rates in Artemisia-sensitized patients is unclear.

Aim: The aim of this study was to estimate the degree of cross-sensitization to Ambrosia/Artemisia allergens in citizens of Poznan (Western Poland). This area is covered by extensive Artemisia populations but does not currently have local Ambrosia populations.

Material and methods: Sera of 119 patients were tested by fluoroenzyme immunoassay (CAP-FEIA system) against pollen allergen extracts of Artemisia vulgaris and Ambrosia artemisiifolia, an allergenic component of A. vulgaris ( $n$ Art $v 1$ ), and an allergenic component of $A$. artemisiifolia $(n A m b$ a 1). Skin prick tests (SPTs, $n=86$ ) were performed with pollen allergen extracts of $A$. vulgaris and A. artemisiifolia. Artemisia and Ambrosia pollen in ambient air was collected (1996-2013) by a Hirst type volumetric trap sited at roof level (33 m).

Results: The SPT showed that the prevalence of sensitization to Ambrosia and Artemisia pollen exceeded 3.5\%, and 10.5\%, respectively. The measurements of IgE in blood serum (CAP-FEIA) revealed that among Ambrosia-sensitized patients 90.1\% (20/22 patients) were concomitantly sensitized to Artemisia. 59.1\% (13/22) of these patients reacted to $n$ Art $v 1$, suggesting primary sensitization to Artemisia pollen. Only 2 (9.1\%) patients were mono-sensitized to Ambrosia pollen extract, but surprisingly not to $n A m b$ a 1 .

Conclusions: The LDT Ambrosia pollen had a negligible effect on the rate of sensitization to Ambrosia allergens in Poznan and did not increase the prevalence of sensitization to Artemisia pollen in this region. However, the majority of patients showing hypersensitization to Artemisia pollen might also present symptoms during elevated episodes of LDT of Ambrosia pollen.
\end{abstract}

Key words: Amb a 1, Art v 1, immunoglobulin E (IgE), skin prick test, fluorescence-linked immunosorbent assay.

\section{Introduction}

Allergens released from Artemisia and Ambrosia pollen are an important cause of late-summer allergy worldwide [1-3]. Both genera are phylogenetically related and belong to the Asteraceae family [4]. Artemisia pollen grains contain several types of allergenic proteins, e.g. the major allergen Art v 1 (a two-domain glycoprotein) and Art $v 6$ (a pectate lyase) $[5,6]$. The major allergen of Ambrosia pollen (Amb a 1) also belongs to the pectate lyase protein family and shares $65 \%$ sequence identity with Art v 6 [5]. Another pro- tein characterized from Ambrosia pollen, Amb a 4, is a close homologue of Art $v 1$ [7]. A recent study has shown [8] that these proteins play an important role in Artemisia and Ambrosia pollen allergy and might be responsible for observed cross-sensitization, i.e. the phenomenon of the same IgE binding to several different, but structurally similar allergens, such as Art v 1 and Amb 4 [9]. As a result, patients sensitized to Artemisia pollen may also show allergy reactions when in contact with Ambrosia pollen (and vice versa). However, the cross-sensitization should be clearly distinguished

Address for correspondence: Łukasz Grewling PhD, Adam Mickiewicz University, Faculty of Biology, Laboratory of Aeropalynology, 89 Umultowska St, 61-614 Poznan, Poland, phone: +48 6182957 01, e-mail: lukaszgrewling@gmail.com Received: 13.04.2016, accepted: 23.11.2016. 
from co-sensitization - the simultaneous presence of different IgEs binding to allergens without common structural features, such as Art $v 1$ and Amb a 1. Although the consequences for patients with co- and cross-sensitization are similar, i.e. allergy symptoms to both pollen types, the etiology (causative factor) is different. This may, in turn, affect the overall cost and efficacy of allergy immunotherapy.

Artemisia pollen grains observed in the air of Poland (Central Europe) are mainly released by local populations of Artemisia species, e.g. A. vulgaris, A. campestris and $A$. absinthium [10]. Artemisia vulgaris is the most widely distributed [11] and therefore should be considered as the main pollen contributor. The intensity of Artemisia pollen seasons recorded in Poland is one of the highest in Central and Eastern Europe [12]. In addition, Artemisia pollen seasons in Poznan (Western Poland) have started earlier and increased in length over the last two decades [13]. Artemisia pollen allergens are therefore considered to be one of the most common causes of allergic diseases of the upper respiratory tract in Poland, ranking third behind Poaceae and Betula pollen allergens [1].

In contrast, Ambrosia artemisiifolia (the most common ragweed species) is an invasive weed from North America, which has currently infested many regions in Asia, particularly Eastern China and South Korea [14, 15], Australia [16], and Europe, especially the Pannonian Plain (mainly Hungary and Northern Serbia) as well as parts of France, Northern Italy (Po Valley) and Ukraine [17]. An expansion of the plant's distribution into Central and Northern Europe (e.g. Germany) has also been observed in recent years [18]. In Poznan, however, Ambrosia has only occurred ephemerally and the majority of recorded Ambrosia pollen grains are transported from distant sources, particularly from the Pannonian Plain and Ukraine [19-21]. As a result, exposure to Ambrosia pollen allergens in Poznan depends highly on meteorological conditions facilitating long-distance transport [22].

It is interesting to note that in areas where both plant species are present, e.g. Northern Italy, an unexpectedly high prevalence of concomitant sensitization to these airborne allergens has been recorded [8, 23]. In other words, the expansion of Ambrosia not only resulted in the increase of Ambrosia pollen allergy but also a parallel increase in Artemisia pollen sensitization. This phenomenon might be especially important in such areas as Poland where: (1) a high rate of Artemisia pollen allergy is observed; (2) Ambrosia invasion is still in its initial phase (mainly limited to the south of the country), and the majority of ragweed pollen arrived from distant sources. With overlapping pollination periods and cross-reacting pollen allergens these species may concomitantly affect sensitized patients, hindering appropriate allergy treatment.

\section{Aim}

Therefore, the aim of this study is to determine the prevalence of Artemisia and Ambrosia pollen allergy and to identify the degree of cross-sensitization among citizens of Poznan. In addition, we examined airborne Artemisia and Ambrosia pollen concentrations recorded over the last 18 years, as exposure is an important factor that plays a role in the induction of allergy sensitization.

\section{Material and methods}

\section{Clinical survey}

Clinical studies were performed at the Department of Dermatology, University of Medical Sciences in Poznan. Poznań is the main city of Western Poland (and the fifth largest city in Poland) with a population of 250000 [24]. The examined group included 119 consecutive patients (48 males and 71 females), aged 3-66 years. Mean age was 22.8 years. Patients were hospitalized, or attended our outpatient clinic. They presented various manifestations of atopy: mostly atopic dermatitis (83 patients $70 \%$ of examined group), allergic rhinitis and conjunctivitis (29 patients $-24 \%$ of examined group) and asthma (7 patients $-6 \%$ of entire group). All patients were residents of Poznan and the surrounding area. In all recruited patients, total and antigen-specific IgE (as IgE) levels were measured in serum using fluoroenzyme immunoassay (FEIA) (CAP System 100, Phadia) against:

- allergen extract of Artemisia vulgaris pollen,

- allergen extract of Ambrosia artemisiifolia pollen,

- allergenic component Artemisia vulgaris (nArt v 1),

- allergenic component of Ambrosia artemisiifolia

(nAmb a 1).

Fluoroenzyme immunoassay (CAP System FEIA Phadia) was used according to the producer's instructions. Results were presented as $\mathrm{kU} / \mathrm{l}$ and interpreted according to the age standard (total lgE), or interpreted as classes (aslgE) - an antibody level lower than $0.35 \mathrm{kU} / \mathrm{l}$ was interpreted as "serum antibodies undetectable".

On the basis of obtained results, the patients were divided into 3 subgroups:

- Subgroup I. Detectable serum antibodies against Artemisia and Ambrosia pollen extracts (Art+/Amb+), crosssensitized patients.

- Subgroup II. No detectable serum antibodies against Artemisia pollen extract, but detectable against Ambrosia (Art-/Amb+), patients mono-sensitized to Ambrosia pollen.

- Subgroup III. Detectable serum antibodies against Artemisia, but not against Ambrosia pollen extract (Art+l Amb-), patients mono-sensitized to Artemisia pollen.

Within these three subgroups, the number of patients with positive reactions to particular allergenic components nArt $v 1 / n A m b$ a 1 was calculated. Asero et al. [8] stated that the major Artemisia pollen allergen (Art $\vee 1$ ) can be considered as the best marker of primary Artemisia sensitization. On the other hand, due to the high cross-reactivity between Amb a 1 and Art $v 6$, it is not possible to distinguish between co- and cross-sensi- 
tization in patients reacting to both major Artemisia and Ambrosia pollen allergens ( $n$ Art $v 1+/ n A m b$ a $1+$ ). As we did not include Art $v 6$ in the FEIA test, all patients showing reactions to Artemisia and Ambrosia pollen extracts/ allergens will be considered, in this study, as cross-sensitized. If sensitization to $n$ Art $v 1$ was observed (Art+l $A m b+$ and $n A r t v 1+$ ), patients were further classified as primary sensitized to Artemisia.

In addition, skin prick tests (SPTs) were performed on a total of 86 patients (72\% of the 119 patients examined). It was not possible to carry out SPTs on the remaining 33 patients because of significant exacerbations of skin inflammatory lesions and constant administration of anti-inflammatory and anti-allergic treatment. The SPTS were performed using airborne allergen extracts (Allergopharma GmbH \& Co. KG, Reinbek, Germany): Artemisia vulgaris and Ambrosia artemisiifolia. Each allergen concentration in a tested substance was expressed as biological units (BE/ml or SBE/ml) and/or PNU.

The SPTs were applied to the skin on the inner part of the forearm, approximately $5 \mathrm{~cm}$ from the wrist and 3-5 $\mathrm{cm}$ from popliteal fossa. The SPTs were examined 20 min after application and the results were presented as the mean diameter of the wheal and erythema, but also on a "plus" scale by comparing the diameters of allergen wheal and control wheal (both positive and negative control). In addition, a doubtful result was defined as an allergen wheal with mean diameter equal to or larger than the half of the mean diameter of a histamine wheal [25].

\section{Pollen monitoring}

Artemisia and Ambrosia pollen grains in ambient air were collected (1996-2013) by a volumetric trap of the Hirst design [26] sited at roof level (33 m) approximately $8 \mathrm{~km}$ from Poznan city centre $\left(52^{\circ} 24^{\prime} \mathrm{N} 16^{\circ} 53^{\prime} \mathrm{E}\right)$. The pollen counting methods used in Poznan during the years studied have previously been described in detail [27]. Daily averages of airborne Artemisia and Ambrosia pollen counts were converted to concentrations and expressed as particles per cubic metre of air $\left(\mathrm{P} / \mathrm{m}^{3}\right)$ [28].
The number of days with daily mean Artemisia and Ambrosia pollen concentrations $\geq 30 \mathrm{P} / \mathrm{m}^{3}$ was extracted from the pollen database. The threshold value $(\geq 30 \mathrm{P} /$ $\left.\mathrm{m}^{3}\right)$ was chosen based on the atmospheric concentrations of Artemisia and Ambrosia pollen often reported to evoke allergic symptoms (De Weger et al. [29] and references therein). Next, the probability risk $(p)$ of recording at least 1, 3, 5, 7 and 10 days with an elevated daily mean Artemisia and/or Ambrosia pollen level $\left(\geq 30 \mathrm{P} / \mathrm{m}^{3}\right)$ during every decade from the beginning of July to the end of September was calculated. The following descriptors of probability were applied (adapted from [30]: very low (0.0 $\leq p \leq 0.25)$, low $(0.25<p \leq 0.50)$, medium $(0.5<p \leq$ $0.75)$, high $(0.75<p \leq 0.90)$, very high $(0.90<p \leq 1.00)$.

\section{Results}

\section{Clinical survey}

FEIA: Out of all recruited patients $(n=119)$, positive results for Artemisia and/or Ambrosia allergen extracts were obtained in 29 patients (29/119 - 24.4\%) (Table 1).

Twenty-two (18.5\%) patients reacted to Ambrosia pollen extract (Subgroups I and II):

- The majority of these patients (20/22 - 90.1\%) were also sensitized to Artemisia pollen extract, and 59.1\% (13/22) of them reacted to $n$ Art $v 1$, suggesting primary sensitization to Artemisia pollen.

- Eight patients (8/22 -36.4\%) did not react to $n A m b$ a 1 and $n$ Art $\vee 1$; they could therefore be sensitized to other (minor) Ambrosia/Artemisia pollen allergens. Six of them (Subgroup I; Art+/Amb+) were potentially cross-sensitized, and the remaining 2 (Subgroup II, Art-/Amb+) were mono-sensitized to Ambrosia pollen, but surprisingly not to the major Ambrosia pollen allergen - nAmb a 1.

- Four patients (4/22 - 18.2\%) reacted to the major Ambrosia pollen allergen - nAmb a 1, but only 1 patient did not show concomitant reaction to $n$ Art $v 1$. As this patient also reacted to Artemisia pollen extract (Art+),

Table 1. Results of FEIA grouped according to hypersensitivity to Ambrosia and/or Artemisia pollen extract detected in 119 examined patients

\begin{tabular}{|c|c|c|c|c|c|}
\hline \multicolumn{2}{|c|}{ Clinical test } & \multicolumn{3}{|c|}{ Ambrosia and Artemisia allergen extracts (subgroups) } & \multirow[t]{2}{*}{ Sum } \\
\hline & & $\begin{array}{c}\text { Subgroup I } \\
\text { Art+/Amb+ (number } \\
\text { of patients; \%) }\end{array}$ & $\begin{array}{c}\text { Subgroup II } \\
\text { Art-/Amb+ (number } \\
\text { of patients; } \% \text { ) }\end{array}$ & $\begin{array}{c}\text { Subgroup III } \\
\text { Art+/Amb- (number } \\
\text { of patients; \%) }\end{array}$ & \\
\hline & & $20 / 119(16.8 \%)$ & $2 / 119(1.7 \%)$ & $7 / 119(5.9 \%)$ & $29 / 119(24.0 \%)$ \\
\hline \multirow{4}{*}{ 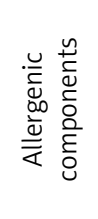 } & $n A m b$ a $1(+) / n A r t \vee v 1(+)$ & $3(15 \%)$ & 0 & 0 & $3(10.4 \%)$ \\
\hline & $n A m b$ a $1(+) / n A r t$ v $1(-)$ & $1(5 \%)$ & 0 & 0 & $1(3.4 \%)$ \\
\hline & $n A m b$ a $1(-) / n A r t v 1(+)$ & $10(50 \%)$ & 0 & $4(57 \%)$ & $14(48.3 \%)$ \\
\hline & $n A m b$ a $1(-) / n A r t v 1(-)$ & $6(30 \%)$ & $2(100 \%)$ & $3(43 \%)$ & $11(37.9 \%)$ \\
\hline
\end{tabular}


A

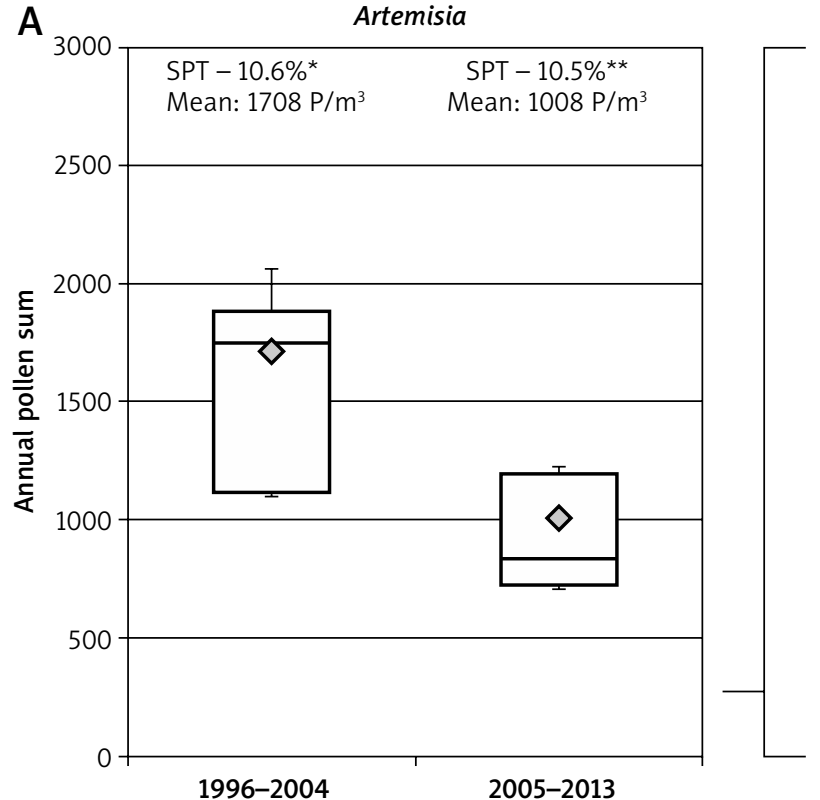

B

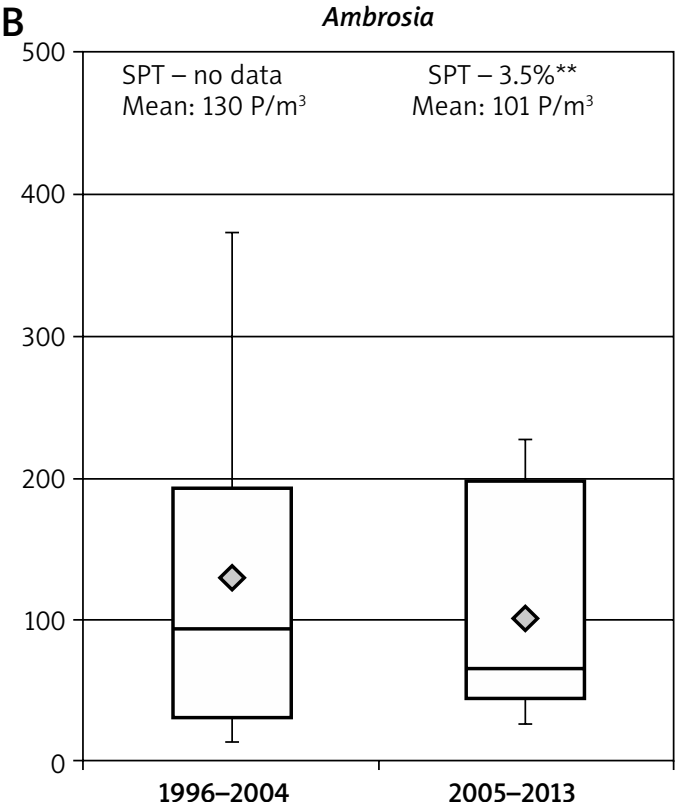

Figure 1. Comparison of the annual sum of airborne Artemisia (A) and Ambrosia (B) pollen between 1996-2004 and 2005-2013, and SPT values against Ambrosia and Artemisia pollen in Poznan. Data collection: ${ }^{*} 2002-2004$ from Stach et al. (2005); ${ }^{* \star 2010-2012 ~ f r o m ~ t h i s ~ s t u d y ~}$

there is a high chance that the reaction to $n A m b$ a 1 resulted from the cross-sensitivity to Art $\vee 6$.

Twenty-seven patients were sensitized to Artemisia pollen extract (20 from Subgroup I and 7 from Subgroup III). $74.1 \%$ (20/27) of them reacted to Ambrosia pollen extract. A total of $63 \%$ (17/27) showed reactions to the major Artemisia pollen allergen $n$ Art $v 1$.

SPT: Of the 86 atopic patients examined, a total of 16 patients presented either positive $(9 / 86-10.5 \%)$ or doubtful (7/86 - 8\%) results for Artemisia allergen extract (Figure 1). With respect to the Ambrosia allergen extract, 3 patients exhibited positive (3/86-3.5\%) and 9 patients doubtful ( $9 / 86-10.5 \%)$ SPTs. Simultaneously positive and/or doubtful SPT results for both allergens were obtained in 9 out of 86 patients (10.5\%).

\section{Aerobiological data}

During the examined period (July-September) the highest probability of recording at least 1 day with an elevated Artemisia pollen level $\left(\geq 30\right.$ Artemisia $\mathrm{P} / \mathrm{m}^{3}$ daily average) was observed in the $1^{\text {st }}$ and $2^{\text {nd }} 10$-day period in August ( $p=0.89$ ) (Figure 2 A). During the $1^{\text {st }} 10$-day period the probability was also high for $\geq 3$ days $(p=0.83$ ) and medium for $\geq 5$ and $\geq 7$ days with $\geq 30$ Artemisia $\mathrm{P} / \mathrm{m}^{3}$ ( $p=0.72$ and $p=0.61$, respectively). In relation to Ambrosia pollen, the probability of exceeding the threshold value ( $\geq 30$ Ambrosia $\mathrm{P} / \mathrm{m}^{3}$ daily average) at least once during a 10-day period was the highest in the $3^{\text {rd }}$ 10 -day period in August and the $1^{\text {st }} 10$-day period in September ( $p=0.28$ and $p=0.22$, respectively) (Figure $2 \mathrm{~B}$ ). In general, the probability of recording elevated daily mean Ambrosia pollen levels during selected 10-day periods was very low or low (never exceeding $\geq 0.30$ ). When both taxa were considered together (Figure $2 \mathrm{C}$ ) the most distinct differences were observed in the $3^{\text {rd }} 10$ day period in August, when the probability of recording at least one day with mean daily Artemisia or Ambrosia pollen levels $\geq 30 \mathrm{P} / \mathrm{m}^{3}$ increased to 0.39 . However, the probability of simultaneously observing elevated daily average concentrations of pollen $\left(\geq 30 \mathrm{P} / \mathrm{m}^{3}\right)$ from both pollen taxa in the same 10-day period was very low (e.g. $p=0.19$ in the $3^{\text {rd }} 10$-day period of August) (Figure $2 \mathrm{D}$ ).

\section{Discussion}

The prevalence of pollen allergy to particular plant species is closely related to the geographical location, and more specifically to the intensity of pollen exposure in that area. In Poland, where Artemisia pollen is considered to be an important aeroallergen, the prevalence to Artemisia pollen allergens is over $20 \%$ and one of the highest in Europe [1]. In our study, depending on tests used, the prevalence varies from $10.5 \%$ (positive reaction in SPT), to $15.1 \%$ (positive reaction to Art $\vee 1$ ), and $22.7 \%$ (positive reaction to Artemisia pollen extract). It is worth noting that among patients sensitized to Artemisia pollen extract (FEIA), 63\% reacted positively to the allergenic component $n$ Art $v 1$ (the major Artemisia pollen allergen). The remaining Artemisia-hypersensitive patients presumably reacted to other Artemisia pollen allergens. For instance, according to Gadermaier et al. [31] Art v 3 can be considered as a new major Artemisia pollen allergen, with the 

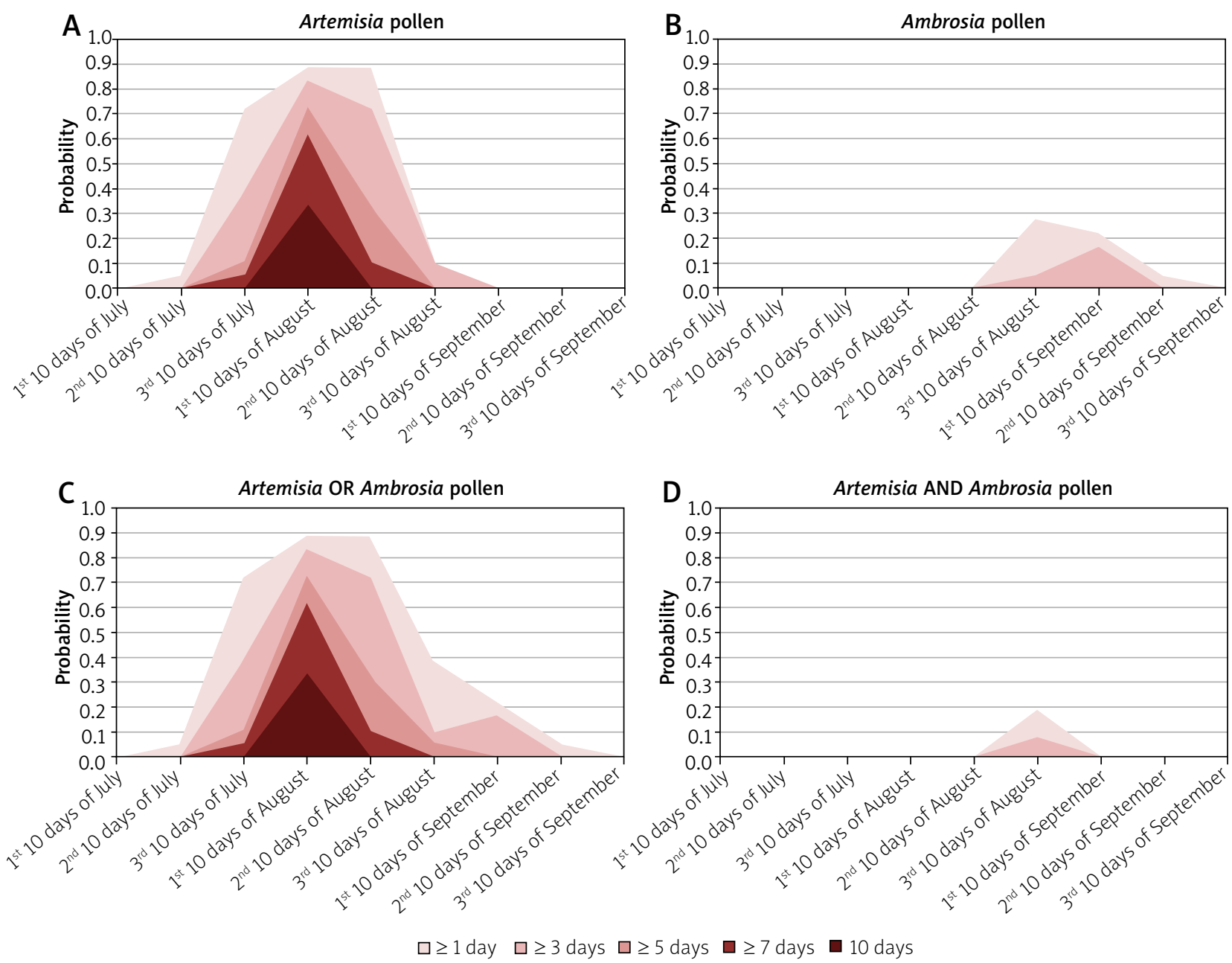

Figure 2. Probability of recording a certain number of days with elevated mean daily Artemisia (A), Ambrosia (B), Artemisia OR Ambrosia (C), and Artemisia AND Ambrosia (D) pollen concentrations ( $\left.\geq 30 \mathrm{P} / \mathrm{m}^{3}\right)$ in the air of Poznan during every 10-day period from the beginning of July to the end of September

prevalence of reactivity among Artemisia pollen-sensitized individuals reaching $85 \%$. The comparison of SPT results obtained in this study with results obtained in a previous analysis conducted during 2002-2004 [32] shows that the rate of sensitization to Artemisia pollen has not markedly changed (from 10.6\% to 10.5\%). Although the pollen level of Artemisia is gradually decreasing in Poznan (likely due to drier summers and reduction of suitable habitats) [13], Artemisia still represents a major source of allergenic sensitization in atopic patients, with stable prevalence over the last decade. These results are in contrast with Northern Italy, where the prevalence of Artemisia sensitivity has increased dramatically during recent decades in parallel with the spread of Ambrosia [33].

For Ambrosia, the highest rate of allergy is observed in countries that are significantly infested by this plant, such as Hungary and France [1]. On the other hand, there is almost no sensitization to Ambrosia pollen allergens in Scandinavia (a region with negligible local sources). The estimated prevalence of sensitization to Ambrosia pollen in Poznan (3.5\%) is similar to that observed in Scandinavia (i.e. $2.3 \%$ in Finland), and lower than in neighbouring countries, e.g. $14.4 \%$ in Germany [1] and around $20 \%$ in Czech Republic [34]. It is also lower than the rate of sensitization to Ambrosia pollen allergens observed in other Polish cities, e.g. 10.8\% in Lodz (Central Poland) [1], and almost $50 \%$ of patients reacted to Ambrosia pollen allergens in Krakow (Southern Poland) [35]. These two cities are located further south than Poznan, and as such are nearer to the northern distribution range of Ambrosia in Europe [17]. Moreover, in Southern Poland Ambrosia artemisiifolia occurs in several well-established populations (> 1000 individuals), becoming a distinct local source of Ambrosia pollen [36].

It should, however, be noted that exposure to pollen is not only related to the plant's distribution area but may also depend on the ability of pollen to be transported over long distances. Episodes of long-distance transport (LDT) of Ambrosia pollen from infested to "ragweed-free" areas, such as Poznan, have been detected over the last 
decades [19-21]. A recent study [37] also revealed that these pollen grains maintain their allergic potency during the atmospheric transport and therefore are equipped to induce allergic reactions in sensitized patients. However, it is still unclear whether this may affect the overall prevalence of Ambrosia pollen allergy. For instance, Cecchi et al. [38] observed that the prevalence of Ambrosia sensitization remains low $(<10 \%)$ in Northern Italy, where people are only exposed to LDT Ambrosia pollen. The same situation can be observed in Poznan. We found that the probability of recording high atmospheric concentrations of Ambrosia pollen in Poznan is low or very low $(p<0.30)$. In addition, as previous studies revealed [20, 22], episodes of LDT of pollen are short (lasting 1-2 days) and usually not very intense. It therefore seems that LDT episodes are too intermittent to markedly influence the prevalence of allergy. On the other hand, the distribution range area of Ambrosia in Europe is changing, mainly expanding into northerly areas [39]. We may therefore expect that the frequency and magnitude of LDT episodes will increase in areas such as Poznan as a product of reduced distance to the pollen source. As a consequence, it may cause the prevalence of sensitization to Ambrosia pollen allergy to increase, as seen in Germany [1].

Due to the cross-sensitization between Artemisia and Ambrosia pollen allergens, the expansion of ragweed may be particularly important for people already sensitized to Artemisia. In our study, almost $75 \%$ of patients sensitized to Artemisia pollen extract showed positive reactions to Ambrosia pollen extract. In addition, possible cross-sensitization was observed in $55 \%$ of patients with positive reactions to Artemisia and Ambrosia pollen extract (Subgroup I). The majority of these patients were primarily sensitized to Artemisia. As a result, we should expect that over half of patients showing hypersensitisation to Artemisia pollen might also present symptoms during elevated episodes of LDT of Ambrosia pollen. This is most likely to occur at the end of August and beginning of September, i.e. the period with the highest probability of recording high concentrations of Ambrosia pollen in the air. Although the risk is still low, this should be taken into account when investigating unusual occurrences of allergy symptoms in sensitized patients during the late Artemisia pollen season.

Six of the patients (27.3\%) belong to Subgroup I (Art+/ Amb+), suggesting cross-sensitization, likely to pan-allergens such as profilins (e.g. Amb a 8 and Art a 4) or calciumbinding proteins (e.g. Art $\vee 5, A m b$ a 9 and Amb a 10) [40]. In contrast to the high prevalence of cross-sensitization among investigated patients with Artemisia and Ambrosia pollen allergy, the frequency of possible co-sensitization was rather low (15\%). In addition, as we did not investigate the reactivity to Art $\vee 6$ (which is a homologue of Amb a 1), we cannot exclude the possibility that these patients were in fact cross-sensitized. The low prevalence of co-sensiti- zation observed in Poznan concurs with the findings from other European studies. For instance, in Switzerland, the observed sensitization to Ambrosia was in most cases a consequence of a primary sensitization to Artemisia [41], whilst no co-sensitized patients have been found in Northern Italy [8].

\section{Conclusions}

Western Poland is currently a ragweed free area, without local plant populations, and the majority of pollen grains recorded in Poznan are transported from very far away. However, in recent decades the distance from the nearest Ambrosia sources has been gradually decreasing. Ambrosia has infested areas in Northern Europe; it has been observed in Eastern Germany and Southern Poland. The "ragweed pollen noose" is slowly tightening... how this situation will affect the allergic population of Poznan is still uncertain. However, it seems that nowadays, Ambrosia pollen does not pose a high allergenic risk in Poznan. The probability of recording elevated mean daily Ambrosia pollen levels is still low and limited to a 20-day period (in late August and early September). In addition, the chances of observing high concentrations of Artemisia and Ambrosia pollen in the air at the same time are even lower, which should be helpful information for physicians choosing appropriate allergy immunotherapy. Finally, the prevalence of Ambrosia pollen allergy is very low, and the co-sensitization to both investigated species is a rather rare phenomenon. This positive information should not, however, lull our sense of security. Ambrosia produces one of the most potent aeroallergens and its distribution range is gradually expanding; it surely requires the highest attention.

\section{Acknowledgments}

Clinical studies were performed at the Department of Dermatology, University of Medical Sciences in Poznan.

This work was funded by Polish National Science Centre grants No. NN404015439 and No. 2011/03/D/ NZ7/06224. The results presented here relate to European COST Action FA1203 "Sustainable management of Ambrosia artemisiifolia in Europe (SMARTER)". We thank A. Szymańska and $Ł$. Kostecki for help with data collection and technical assistance.

\section{Conflict of interest}

The authors declare no conflict of interest.

\section{References}

1. Burbach GJ, Heinzerling LM, Edenharter G, et al. GA2LEN skin test study II: clinical relevance of inhalant allergen sensitizations in Europe. Allergy 2009; 64: 1507-15. 
2. Oswalt ML, Marshall GD. Ragweed as an example of worldwide allergen expansion. Allergy Asthma Clin Immunol 2008; 4: 130-5.

3. Tang R, Sun JL, Yin J, et al. Artemisia allergy research in China. Biomed Res Intern 2015; 2015: 179426.

4. Jäger S. Plant taxonomy and nomenclature. Postep Derm Alergol 2003; 20: 218-26.

5. Jahn-Schmid B, Hauser M, Wopfner N, et al. Humoral and cellular cross-reactivity between Amb a 1, the major ragweed pollen allergen, and its Mugwort homolog Art $\vee 6$. J Immunol 2012; 188: 1559-67.

6. Gadermaier G, Hauser M, Ferreira F. Allergens of weed pollen: an overview on recombinant and natural molecules. Methods 2014; 66: 55-66.

7. Leonard R, Wopfner N, Pabst M, et al. A new allergen from ragweed (Ambrosia artemisiifolia) with homology to Art v 1 from mugwort. J Biol Chem 2010; 285: 27192-200.

8. Asero R, Bellotto E, Ghiani A, et al. Concomitant sensitization to ragweed and mugwort pollen: who is who in clinical allergy? Ann Allergy Asthma Immunol 2014; 113: 307-13.

9. Migueres M, Davila I, Frati F, et al. Types of sensitization to aeroallergens: definitions, prevalences and impact on the diagnosis and treatment of allergic respiratory disease. Clin Transl Allergy 2014; 4: 16.

10. Bogawski P, Grewling Ł, Frątczak A. Flowering phenology and potential pollen emission of three Artemisia species in relation to airborne pollen data in Poznań (Western Poland). Aerobiologia 2016; 32: 265-76.

11. Zając A, Zając M. Atlas rozmieszczenia roślin naczyniowych w Polsce. Distribution atlas of vascular plants in Poland. Instytut Botaniki Uniwersytetu Jagiellońskiego Kraków 2001.

12. Grewling $t$, Šikoparija B, Skjøth CA, et al. Variation in Artemisia pollen seasons in Central and Eastern Europe. Agric For Meteorol 2012; 160: 48-59.

13. Bogawski P, Grewling $Ł$, Nowak M, et al. Trends in atmospheric concentrations of weed pollen in the context of recent climate warming in Poznań (Western Poland). Int J Biometeorol 2014; 58: 1759-68.

14. Oh JW, Lee HB, Kang IJ, et al. The revised edition of Korean calendar for allergenic pollens. Allergy Asthma Immunol Res 2012; 4: 5-11.

15. Chen H, Chen L, Albright TP. Developing habitat-suitability maps of invasive ragweed (Ambrosia artemisiifolia.L) in China using GIS and statistical methods In Lai PC, Mak ASH, (Eds). GIS for Health and the Environment Development in the Asia-Pacific Region: Springer 2007.

16. Bass DJ, Delpech V, Beard J, et al. Ragweed in Australia. Aerobiologia 2000; 16: 107-11.

17. Smith M, Cecchi L, Skjøth CA, et al. Common ragweed: a threat to environmental health in Europe. Environ Int 2013; 61: 115-26.

18. Cunze S, Leiblein MC, Tackenberg O. Range expansion of Ambrosia artemisiifolia in Europe is promoted by climate change. ISRN Ecology 2013; 2013: 610126.

19. Smith M, Skjøth CA, Myszkowska D, et al. Long-range transport of Ambrosia pollen to Poland. Agric For Meteorol 2008; 148: 1402-11.

20. Stach A, Smith M, Skjøth CA, et al. Examining Ambrosia pollen episodes at Poznan (Poland) using back-trajectory analysis. Int J Biometeorol 2007; 51: 275-86.

21. Kasprzyk I, Myszkowska D, Grewling Ł, et al. The occurrence of Ambrosia pollen in Rzeszów, Kraków and Poznań, Poland: investigation of trends and possible transport of Ambrosia pollen from Ukraine. Int J Biometeorol 2011; 55: 633-44.
22. Šikoparija B, Skjøth CA, Alm Kübler K, et al. A mechanism for long distance transport of Ambrosia pollen from the Pannonian plain. Agric For Meteorol 2013; 180: 112-7.

23. Asero R, Wopfner N, Gruber P, et al. Artemisia and Ambrosia hypersensitivity: co-sensitization or co-recognition? Clin Exp Allergy 2006; 36: 658-65.

24. CSO. Area and population in the territorial profile in 2013. Statistical Information and Elaborations. Warsaw: Methodology, Standards and Registers Department. Central Statistical Office 20132013.

25. Kruszewski J, Silny W, Mazurek H, et al. Testy skórne. Standardy w alergologii. Część I. The UCB Institute of Allergy Belgium 2003; 9-29.

26. Hirst JM. An automatic volumetric spore trap. Ann Appl Biol 1952; 39: 257-65.

27. Grewling $Ł$, Jackowiak B, Nowak M, et al. Variations and trends of birch pollen seasons during 15 years (1996-2010) in relation to weather conditions in Poznań (Western Poland). Grana 2012; 51: 280-92.

28. Comtois P. Statistical analysis of aerobiological data. In: Methods in Aerobiology. Mandrioli P, Comtois P, Levizzani V (eds). Pitagora Editrice, Bologna 1998.

29. De Weger LA, Bergmann KC, Rantio Lehtimäki A, et al. Impact of pollen. In: Allergenic Pollen: a Review of the Production, Release, Distribution and Health Impacts. Sofiev M, Bergmann KC (eds). Springer, Dordrecht 2013.

30. Garcia ML. Design and Evaluation of Physical Protection Systems. 2 edn. Butterworth Heinemann 2007.

31. Gadermaier G, Wopfner N, Wallner M, et al. Array-based profiling of ragweed and mugwort pollen allergens. Allergy 2008; 63: 1543-9.

32. Stach A, García-Mozo H, Prieto-Baena JC, et al. Prevalence of Artemisia species pollinosis in Western Poland: impact of climate change on aerobiological trends, 1995-2004. J Investig Allergol Clin Immunol 2007; 17: 39-47.

33. Asero R. Is the strange case of mugwort sensitivity in ragweedallergic subjects coming eventually to a solution? Eur Ann Allergy Clin Immunol 2011; 43: 67-68.

34. Rybníček O, Novotná B, Rybníckova E, et al. Ragweed in the Czech Republic. Aerobiologia 2000; 16: 287-90.

35. Obtulowicz K, Szczepanek K, Myszkowska D. Ambrosia pollen grains in aeroplankton of Krakow and their role in pollen allergy of this region. In: Pollens and Pollinosis: Current Problems: Spiewak R (ed). Institute of Agricultural Medicine, Lublin (Poland) 1995; 56.

36. Tokarska-Guzik B, Bzdęga K, Koszela K, et al. Allergenic invasive plant Ambrosia artemisiifolia L. in Poland: threat and selected aspects of biology. Biodiv Res Conserv 2011; 21: 39-48.

37. Grewling Ł, Bogawski P, Jenerowicz D, et al. Mesoscale atmospheric transport of ragweed pollen allergens from infected to uninfected areas. Int J Biometeorol 2016; 60: 1493-500.

38. Cecchi L, Testi S, Campi P, et al. Long-distance transport of ragweed pollen does not induce new sensitizations in the short term. Aerobiologia 2010; 26: 351-2.

39. Storkey J, Stratonovitch P, Chapman DS, et al. A process based approach to predicting the effect of climate change on the distribution of an invasive allergenic plant in Europe. PLoS One 2014; 12: e88156.

40. Hauser M, Roulias A, Ferreira F, et al. Panallergens and their impact on the allergic patient. Allergy Asthma Clin Immunol 2010; 6: 1.

41. Ackermann-Liebrich A, Schindler C, Frei P, et al. Sensitisation to Ambrosia in Switzerland: a public health threat in waiting. Swiss Med Wkly 2009; 139: 70-5. 